\title{
Evaluating Frictional Temperature Rise in Sliding Surface of Artificial Hip Joint Materials with Different Loading Conditions
}

\author{
B. SAGBAS ${ }^{a, *}$ AND M.N. DURAKBASA ${ }^{b}$ \\ ${ }^{a}$ Department of Mechanical Engineering, Yildiz Technical University, Istanbul, Turkey \\ ${ }^{b}$ Department of Interchangeable Manufacturing and Industrial Metrology, Vienna University of Technology \\ Karlsplatz 13/3113, A-1040 Wien, Austria
}

\begin{abstract}
Friction between articulating surfaces cause temperature rise in acetabular cup and femoral head. This heating may influence the rate of wear, fatigue, creep, oxidative degradation of bearing materials and may terminate surrounding tissue. The objective of this study is to determine temperature rise with different applied load for the articulating surfaces of conventional ultra high molecular weight polyethylene (UHMWPE) and vitamin E blended ultra high molecular weight polyethylene (VE-UHMWPE) acetabular components paired with a ceramic femoral component in bovine calf serum lubrication condition. Additionally frictional torque between the bearing surfaces was measured and friction coefficient was calculated. Frictional measurements of the joints were carried out on a custom made hip joint friction simulator. Various levels of static loads were applied on $28 \mathrm{~mm}$ diameter prostheses. In flexion-extension plane, a simple harmonic oscillatory motion between $\pm 24^{\circ}$ was applied to the UHMWPE acetabular component. The period of motion was $1 \mathrm{~Hz}$ and the tests were run up to 12,000 cycles. Temperature rise in acetabular and femoral component was recorded with embedded thermocouples. The results were compared in terms of UHMWPE and vitamin E blended UHMWPE.
\end{abstract}

DOI: $10.12693 /$ APhysPolA.123.453

PACS: $87.85 . \mathrm{J}-$

\section{Introduction}

Friction between articulating surfaces cause temperature rise in the acetabular cup and femoral head. This heating may influence the rate of wear, fatigue, creep, and oxidative degradation of bearing materials $[1,2]$. Beside this, temperature rise can damage the surrounding tissue and lubricant around the artificial joint and contribute cup loosening [1]. Lu and McKellop reported that frictional heating may promote the protein precipitation from the lubricant. This caused property change of lubricant [3]. Bergmann et al. measured the changes of temperature of hip prosthesis in vivo conditions. They measured the temperature of the hip implant in a patient body after one hour walking. The maximum temperature value was $43.1^{\circ} \mathrm{C}$ [4]. In another study synovial fluid's temperature was found as $46^{\circ} \mathrm{C}$ by $2 \mathrm{D}$ and $3 \mathrm{D}$ finite element analysis. By considering that the biological defects occur at $40^{\circ} \mathrm{C}$, it is clear that frictional heating negatively affects service life of artificial joints $[1,5]$. So measurement of temperature rise and evaluating frictional behavior of the bearing materials is important for development of new materials and designs for artificial joints with long service life [6].

Although ultra high molecular weight polyethylene (UHMWPE) has been the most commonly used bearing material in artificial joints, wear of UHMWPE has been reported to be very serious problem which decreases implant service life [7-10]. So, there has been

*corresponding author; e-mail: bsagbas@gmail.com a need for enhancement of UHMWPE properties to obtain more wear resistant materials and extend the implants life. By modifying the UHMWPE microstructure by radiation-induced cross linking, and various thermal treatments, first generation cross-linked UHMWPEs were developed $[11,12]$. The radiation cross-linking of UHMWPE has showed higher wear resistance than conventional UHMWPE but oxidation resistance, fatigue and fracture resistance has decreased due to the crosslinking of the molecular chains [7, 13-16]. At that point second generation cross-linked UHMWPEs have been introduced which has been developed by adding the $\alpha$-tocopherol or vitamin E, as a natural antioxidant, into UHMWPE to reduce the problems aroused by the post-irradiation thermal treatment [12]. However it was reported that conventional and cross-linked UHMWPE has been prevented from oxidation and delamination by adding vitamin $\mathrm{E}$; frictional heating behavior of vitamin E blended UHMWPE (VE-UHMWPE) has not been reported yet.

The objective of this study was to determine temperature rise with different applied load for the articulating surfaces of conventional UHMWPE and VE-UHMWPE acetabular components paired with a ceramic femoral component in bovine calf serum lubrication condition.

Additionally, frictional torque between the bearing surfaces was measured and friction coefficient was calculated.

\section{Materials and methods}

Acetabular cup samples were machined from Chirulen 1020 and Chirulen 1020 E rods (MediTECH Medical 
Polymers, Vreden, Germany). The inner surface of the samples was machined the same as an acetabular cup and in accordance with ISO 7206-2:2011 and ISO 21535 $[17,18]$. To provide uniform construction for heat dissipation, metal backing or fixing tools were not used except screw to fix the samples. For this reason the outer surfaces of the samples were cylindrical in $40 \mathrm{~mm}$ diameter and three screws were used for fixation. The acetabular cup samples were paired with zirconia ceramic femoral heads. The prostheses are of $28 \mathrm{~mm}$ diameter. Surface roughness of acetabular cups was measured by Taylor Hobson Form Talysurf Intra. Surface roughness of UHMWPE was $0.679 \mu \mathrm{m}$, VE-UHMWPE was $0.647 \mu \mathrm{m}$. These values are suitable for the reference of ISO 7206-2: 2011 [17].

Frictional measurements of the joints were carried out on a custom made hip joint friction simulator. For eliminating experimental inaccuracies the prosthesis was inverted with respect to anatomical position as in previous studies $[2,3,19]$. Applied static loads were $200 \mathrm{~N}$, $750 \mathrm{~N}$, and $1000 \mathrm{~N}$. In flexion-extension plane, a simple harmonic oscillatory motion between $\pm 24^{\circ}$ is applied to the UHMWPE acetabular component. The period of motion is $1 \mathrm{~Hz}$ and the tests are run up to 12000 cycles in $5 \mathrm{ml}$ bovine calf serum (Sigma-Aldrich) lubrication condition. The experimental setup and samples drawing can be seen in Fig. 1a and b.

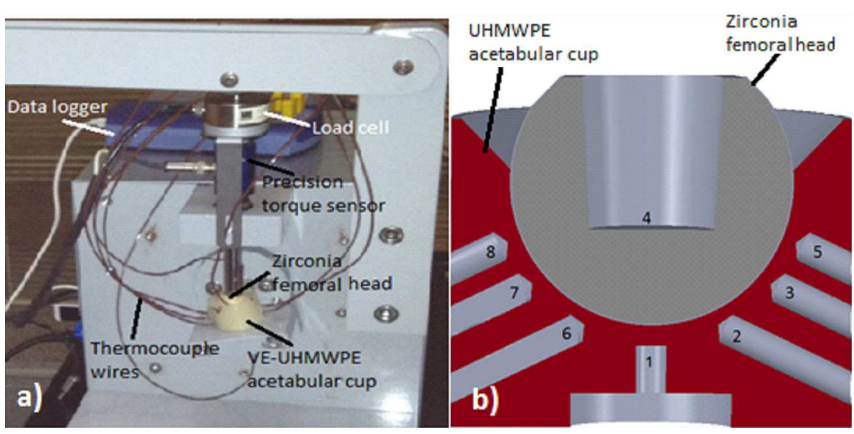

Fig. 1. (a) Experimental setup, (b) drawing of acetabular cup and femoral head with thermocouple holes. The numbers on holes show the location of each thermocouple.

Temperature rise in acetabular cup and femoral component is recorded with embedded thermocouples. For acetabular cup, surface temperature measurements were taken from seven points. $3 \mathrm{~mm}$ diameter holes were drilled into backside of the cups to $0.5 \mathrm{~mm}$ from the surface. After initial calibration of thermocouples, they were adhered in the holes by heat conduction glue. Output signals were collected by a data logger (Pico TC-08) that was connected to computer program. Then the temperature values were calculated according to pre-calibration equation. Additionally frictional torque between the bearing surfaces was measured by torque cell for each loading condition and friction coefficient was calculated.
Because of the ball-in-cup configuration of the hip joint the pressure distribution within the contact area cannot be determined precisely. So the friction coefficient $\mu$ cannot be calculated accurately. Instead of friction coefficient $\mu$ a dimensionless parameter called friction factor was determined by using Eq. (1):

$$
f=\frac{T}{R L} .
$$

Here $f$ is the friction factor, $T$ is the measured torque $(\mathrm{N} \mathrm{m}), r$ is the radius of femoral head $(\mathrm{m}), L$ is the load (N) [20].

\section{Results and discussion}

Frictional temperature rise in acetabular cup and femoral head sliding surfaces top points for different loading conditions can be seen in Fig. 2a and b. Temperature rise increased by increasing normal loading. VE-UHMWPE cup temperature rise was about $1-1.5^{\circ} \mathrm{C}$ lower than conventional UHMWPE cup samples while sliding with zirconia femoral head in bovine calf serum. This result may be explained by surface properties and lubrication regime of the paired surfaces.

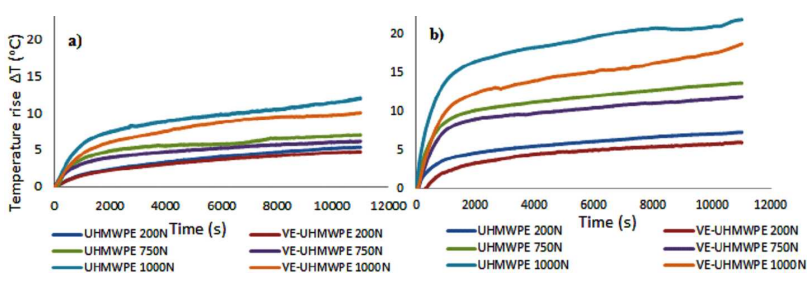

Fig. 2. The temperature rises for both VE-UHMWPE and UHMWPE-zirconia cup-ball pairs top contact points under different loading conditions. (a) Temperatures for cups taken from location 1 thermocouple, (b) temperatures for zirconia femoral head taken from location 4 thermocouple.

Temperature rise in zirconia femoral head was higher than acetabular cup samples because thermal conductivity of VE-UHMWPE and conventional UHMWPE is $0.4 \mathrm{~W} /(\mathrm{m} \mathrm{C})$ and thermal conductivity of zirconia is $1.9 \mathrm{~W} /(\mathrm{m} \mathrm{C})$. So, significant portion of the frictional heat conducted through the zirconia ball. The temperature rise at the location 4 in femoral head was higher for conventional UHMWPE than VE-UHMWPE.

For each loading conditions and each material pairs, temperature rise curve showed similar characteristics as shown in Fig. 2. For each thermocouple location points, the rate of the temperature rise was high up to $2000 \mathrm{~s}$ then the rate was decreasing to reach the steady state. Temperature rise for each location under 1000 N static load can be seen in Fig. 3 .

The temperature values for location 1 and 4 which were the nearest to the normal load axis were the highest, $28^{\circ} \mathrm{C}$ and $36^{\circ} \mathrm{C}$, respectively, for VE-UHMWPE/zirconia and $33^{\circ} \mathrm{C}$ and $39^{\circ} \mathrm{C}$ for UHMWPE/zirconia sliding pairs. In locations $2,3,5,6,7,8$, which were located on 


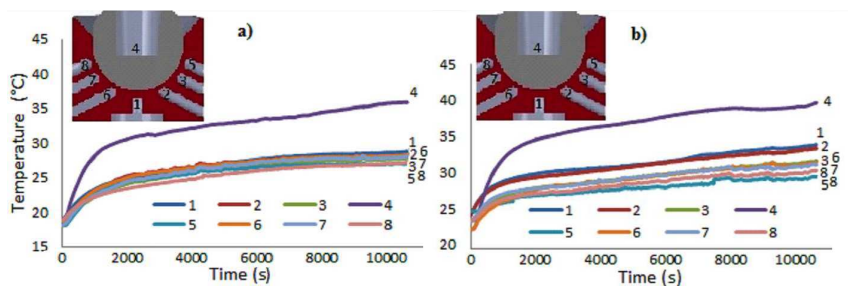

Fig. 3. The temperature rise of the acetabular cup and femoral head for $1000 \mathrm{~N}$ loading condition, taken from 8 different location points as shown in Fig. 1b. (a) For VE-UHMWPE/zirconia, (b) for conventional UHMWPE/zirconia sliding pairs.

the right and left side of the contact point, temperatures distributed symmetrically along the motion direction and they were decreasing while moving away from top contact surface of the materials. The maximum difference was about $1{ }^{\circ} \mathrm{C}$ from the value of the peak temperature. It must be noted that these values were for the thermocouple location points which were $0.5 \mathrm{~mm}$ inside from the surface. So the surface temperatures must have been higher than measured ones.

Frictional torque average values for VE-UHMWPE and conventional UHMWPE were $0.51 \mathrm{Nm}$ and $0.55 \mathrm{Nm}$, and friction coefficients were 0.018 and 0.02 , respectively.

\section{Conclusion}

Significant temperature rise was observed in sliding surface of the hip joint materials. Temperature rise in zirconia femoral head was obviously higher than UHMWPE acetabular cup samples. In VE-UHMWPE surface, about $1-1.5^{\circ} \mathrm{C}$ lower temperature rise was measured than conventional UHMWPE. To make a certain conclusion for comparing the materials frictional heating behavior, further experiments are going on with different material pairs and different lubrication conditions.

\section{Acknowledgments}

This research has been supported by Yldız Technical University Scientific Research Projects Coordination Department, project number: 2011-06-01-DOP03.

The authors would like to thank MediTECH Medical Polymers (Vreden, Germany) for material support of the study.

\section{References}

[1] C.C. Hu, J.J. Liau, C.Y. Lung, C.H. Huang, C.K. Cheng, Mater. Sci. Eng. C 17, 11 (2001)

[2] Y.-S. Liao, H. McKellop, Z. Lu, P. Campbell, P. Benya, Biomaterials 24, 3047 (2003).

[3] Z. Lu, H. McKellop, Proc. Inst. Mech. Eng. Part H: J. Eng. Med. Part H, 211, 101 (1997).

[4] G. Bergmann, F. Graichen, A. Rohlmann, N. Verdonschot, G.H. Van Lenthe, J. Biomech. 34, 421 (2001)

[5] G. Bergmann, F. Graichen, A. Rohlmann, N. Verdonschot, G.H. Van Lenthe, J. Biomech. 34, 429 (2001)

[6] G.N. Dong, M. Hua, J. Li, K.B. Chuah, Mater. Design 28, 2402 (2007)

[7] H. Bhatt, T. Goswami, Biomed. Mater. 3, 1 (2008)

[8] D. Xiong, S. Ge, Wear 250, 242 (2001)

[9] G. Lewis, Biomaterials 22, 371 (2001).

[10] S.M. Kurtz, O.K. Muratoglu, M. Evans, A.A. Edidin, Biomaterials 20, 1659 (1999)

[11] J.L. Tipper, A.L. Galvin, S. Williams, H.M.J. McEwen, M.H. Stone, E. Ingham, J. Fisher, J. Biomed. Mater. Res. Part A 78A, 473 (2006)

[12] C. Vaidya, E. Alvarez, J. Vinciguerra, D.A. Bruce, J.D. DesJardins, Proc. Inst. Mech. Eng. H 225, 1 (2011)

[13] S.M. Kurtz, UHMWPE Biomaterials Handbook, 2nd ed., Elsevier Inc., Academic Press, Burlington 2009, p. 227.

[14] C.A. Jacobs, C.P. Christensen, A.S. Greenwald, H. McKellop, J. Bone Joint Surg. Am. 89, 2779 (2007).

[15] L. Bradford, D.A. Baker, J. Graham, A. Chawan, M.D. Ries, L.A. Pruitt, J. Bone Joint Surg. 86A, 1271 (2004).

[16] J. Furmanski, S. Gupta, A. Chawan, A. Kohm, J. Lannutti, B. Jewett, L.A. Pruitt, M.D. Ries, J. Bone Joint Surg. 89, 2266 (2007)

[17] ISO 7206-2:2011, Implants for surgery — Partial and total hip joint prostheses, Part 2: Articulating surfaces made of metallic, ceramic and plastics materials.

[18] ISO 21535:2001, Non-active surgical implants — Joint replacement implants - Specific requirements for hip-joint replacement implants.

[19] Y. Yan, A. Neville, D. Dowson, S. Williams, J. Fisher, Wear 267, 683 (2009)

[20] Z.M. Jin, M. Stone, E. Ingham, J. Fisher, Current Orthopaedics 20, 32 (2006) 